\title{
Patrimônio arquitetônico e documental: referências da institucionalização da assistência em saúde na Bahia e no Brasil
}

\author{
Architectural and documental heritage: references on the \\ institutionalization of health care in Bahia and in Brazil
}

\author{
Joseane Paiva Macedo Brandão \\ Doutoranda do Programa de Pós-graduação em Sociologia/Universidade Federal de Sergipe.
} bjoseane@hotmail.com

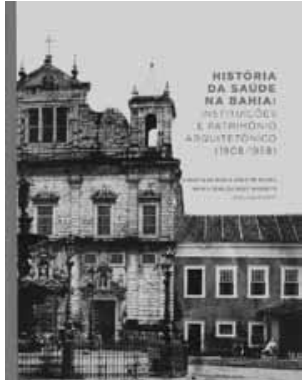

BARRETO, Maria Renilda Nery; SOUZA, Christiane Maria Cruz de (Org.). História da saúde na Bahia: instituições e patrimônio arquitetônico (1808-1958). Rio de Janeiro: Editora Fiocruz; Barueri: Manole, 2011. 149p.
( livro História da Saúde na Bahia: instituições e patrimônio arquitetônico (1808-1958) é fruto do "Inventário do patrimônio cultural da saúde: bens edificados e acervos", um projeto desenvolvido pela Casa de Oswaldo Cruz/Fundação Oswaldo Cruz e pelo Instituto Federal de Educação, Ciência e Tecnologia da Bahia e apresenta o estudo e a identificação do patrimônio arquitetônico e documental de hospitais e outros institutos de assistência médica e pesquisa científica da cidade de Salvador. Além dos textos, acompanha o livro um CD-ROM com dados de 37 dessas instituições ainda existentes na capital baiana. Para cada uma delas constam informações como histórico, registros iconográficos, descrição arquitetônica e uso atual.

Em termos patrimoniais, a obra representa a salvaguarda e valorização do patrimônio arquitetônico e documental de hospitais, instituições de assistência médica, institutos de pesquisa científica criados no país entre o início do século XIX e a década de 1950, alargando o conjunto de objetos patrimoniais dignos de análise e participação no patrimônio cultural brasileiro. Muitos dos bens culturais considerados pela publicação são referências da origem, evolução e institucionalização das políticas de saúde no Brasil, especificamente na Bahia.

O recorte temporal escolhido relaciona-se com a institucionalização das ciências no Brasil, em especial da ciência médica, com a criação das primeiras escolas médico-cirúrgicas na Bahia e no Rio de Janeiro no início do século XIX e a criação do Ministério da Saúde nos anos 1950, consolidando o campo institucional da saúde pública no Brasil e mostrando, ainda, a relação desse campo com o modernismo na arquitetura. Além disso, a obra trata da transição entre dois modelos de assistência à saúde na Bahia e no Brasil. 
Mudanças institucionais importantes ocorreram na passagem do século XIX para o XX no Brasil. Com a proclamação da República, uma nova elite de intelectuais, artistas, políticos e militares, com plataforma baseada em diretrizes científicas e técnicas, empreende a atualização das estruturas do Império com o objetivo de modernizar o país. As mudanças institucionais na assistência em saúde são 'boas para pensar' na modernização em curso nesse período no Brasil e nos elementos da 'revolução científico-tecnológica' (Sevcenko, 1998) à brasileira.

O primeiro capítulo, "A Santa Casa da Misericórdia da Bahia e a assistência aos doentes no século XIX", de autoria de Maria Renilda Nery Barreto, mostra o importante papel das santas casas de misericórdia na estruturação do Império português no Brasil, onde teceram forte aliança com o poder central, do período colonial à República, com o estabelecimento de relações muitas vezes tensas entre as misericórdias e as elites locais. A autora afirma que o modelo de composição das santas casas implantado pela colonização, de tendência elitista, parental e oligárquica, se reproduziu até as primeiras décadas da República.

O papel de cuidar dos pobres leva as misericórdias a reivindicar a incorporação de hospitais e leprosários desde o século XVII, o que gerou benefícios econômicos e aumento de sua visibilidade, atestando o monopólio da administração hospitalar por essas instituições até as primeiras décadas do século XX. Entretanto, a análise do perfil da população que frequentou o Hospital São Cristóvão (principal Hospital da Misericórdia na capital baiana do século XVI ao XIX), composta por homens brancos, estrangeiros e com ocupação definida (p.20), permite afirmar que as ações de assistência aos doentes das santas casas visavam atender demandas sociais para além da benemerência cristã. Conclui-se, assim, a articulação da atuação das santas casas com os interesses dos grupos sociais locais para responder aos desafios e contextos político-econômicos específicos, sendo, nesse caso, expressão da dinâmica comercial e marítima da cidade de Salvador (p.15).

O segundo capítulo, "Saúde pública e assistência na Bahia da Primeira República (1889-1929)", de autoria de Christiane Maria Cruz e Souza e Gisele Sanglard, trata das transformações relativas à assistência em saúde em Salvador ao longo da Primeira República. Inicialmente, as autoras desenvolveram uma análise comparativa da organização da assistência pública e privada na Bahia. Basearam-se para tal na obra produzida por Francisco Vicente Vianna (diretor do Arquivo Público da Bahia) em 1893 e no quadro da assistência em saúde na Bahia ao final da Primeira República (1929). O texto demonstra que em 1893 a assistência na Bahia era dominada pela filantropia em contraste com a presença crescente dos poderes públicos constituídos (estadual e federal) em 1929.

Com a proclamação da República, a organização da saúde pública é descentralizada, e a constituição dessas políticas na Bahia passa a preocupar a elite local. As autoras ressaltam o papel de J.J. Seabra, ministro da Justiça e Negócios Interiores, na gestão de Rodrigues Alves (1902-1906) e ministro de Viação e Obras Públicas, na gestão de Hermes da Fonseca (19101912), que, devido ao caráter centralizador de sua gestão, permitiu que muitas das obras de equipamentos de saúde fossem finalizadas e seus respectivos serviços disponibilizados para a população. Alguns dos exemplos destacados foram os institutos Bacteriológico, Antirrábico e Vacinogênico, construídos na gestão de Araújo Pinho (1908-1911), mas só inaugurados na gestão de J.J. Seabra, e também as instalações da Assistência Pública, iniciada no mandato do 
intendente Júlio Viveiros Brandão, mas que, por falta de recursos, foi assumida e inaugurada pelo governo de J.J. Seabra em 1916 (p.58-59).

Além disso, esse político baiano promoveu a reforma da cidade de Salvador, objetivando sanear e ordenar o espaço público, o porto incluído, o que atendia às necessidades da elite local. As ações das autoridades eram informadas pela ideologia do higienismo ${ }^{1}$, fortemente arraigada nas práticas de médicos, engenheiros e filantropos no final do século XIX e início do XX. Nesse sentido, tal como Chalhoub (1996) tratou em seu trabalho sobre cortiços e epidemias no Rio de Janeiro, a ideia de técnica e competência na gestão pública passa a guiar as ações dos agentes em saúde, dissimulando o sentido classista de decisões políticas.

Finalmente, as autoras demonstram o crescimento, na cidade de Salvador durante a Primeira República, de instituições de saúde filantrópicas, bem como aquelas constituídas pelos poderes públicos, ressaltando a necessidade de não perder de vista as fronteiras 'porosas' entre a assistência filantrópica e a pública. Ao analisar as mudanças do campo institucional da assistência em saúde na Bahia revelam o importante papel das elites locais que, atuando por meio da filantropia, contribuem na legitimação do discurso médico que passa a orientar a organização da assistência pública em Salvador no período.

O terceiro capítulo, "Medicina, filantropia e infância na Bahia: um hospital para crianças (1920-1930)", de autoria de Luiz Otávio Ferreira e Maria Martha de Luna Freire, trata da mobilização social em torno da construção de um hospital exclusivo para crianças em Salvador entre 1920 e 1930. Os autores consideram esse episódio representativo das transformações institucionais da assistência à saúde infantil ocorridas na primeira metade do século XX no Brasil resultantes da conjugação de interesses e valores da medicina higienista e de entidades filantrópicas (p.74).

Nessa época, pediatria e puericultura eram especialidades médicas em busca de autoridade científica, e sua aliança com a filantropia combinava perspectiva médica e social, fonte de modelos institucionais e motivações ideológicas para a formulação e implantação de políticas públicas assistenciais de proteção à saúde infantil após 1930 (p.74-75).

A assistência à saúde infantil representava uma 'cruzada civilizatória' em que principalmente mulheres das elites locais e médicos uniram-se contra as elevadas taxas de mortalidade infantil, consideradas consequências de hábitos culturais 'pré-científicos', reproduzidos sobretudo em meio aos mais pobres. Nesse período, a relação entre classes populares e epidemias se estabelece nas políticas de saúde que, assim, acabam por articular-se com as políticas de controle social. Por sua vez, os higienistas aumentam seu protagonismo na decisão dos rumos das políticas urbanas ao ocupar cargos a importantes na administração pública, como demonstra Chalhoub (1996) no seu estudo sobre o Rio de Janeiro. Entretanto, esse quadro se repetia nas demais capitais provinciais, como Salvador, como afirma Marins (1998, p.162): "as dificuldades geradas pela experiência fragmentária e irresoluta das reformas urbanas do Rio de Janeiro repercutiram nas maiores cidades da República, que tentavam reproduzir nos estados os modelos europeus ou cariocas de readequação espacial".

A fundação do Instituto de Proteção e Assistência à Infância da Bahia em 1903 condensa institucionalmente essa nova ideologia acerca do modelo assistencial para a infância. O modelo caritativo de assistência à criança entra em declínio desde o final do século XIX no Brasil. Na Bahia, a transição para o modelo médico-filantrópico se inicia quando a Roda dos Expostos 
de Salvador é transferida para instalações próprias e passa a ser denominada Asilo Nossa Senhora da Misericórdia, sendo administrada por irmãs de caridade de São Vicente de Paula, substituídas por pedagogas e médicos na década de 1910. A atuação da Liga Bahiana contra a Mortalidade Infantil, criada em 1923 por um grupo de médicos e um rico comerciante local, significou a implantação definitiva do novo modelo de assistência à saúde infantil (p.82).

A construção de um hospital para crianças, concretizada em 1936, foi justificada por ideias balizadas pela ciência moderna, como a necessidade de cuidados e espaços de tratamento peculiares para a infância e também o caráter pedagógico da higiene materno-infantil e seu pressuposto de responsabilização individual. A filantropia, reforçada como virtude social e atitude cívica, e o nacionalismo faziam parte da cultura da elite urbana brasileira na época, conferindo prestígio e aura de modernidade a esse grupo. O texto traz uma descrição interessante sobre as negociações do local do hospital, bem como os debates na imprensa que dão relevo à dimensão política dessa questão para as elites locais na República.

O quarto e último capítulo, "Arquitetura moderna e as instituições de saúde na Bahia nas décadas de 1930 a 1950", de autoria de Nivaldo Vieira de Andrade Junior, concentra sua análise nos exemplares modernistas da arquitetura hospitalar na Bahia, com foco no valor arquitetônico dessas edificações, bem como em sua participação "no processo de modernização estética e de infraestruturação de Salvador e outras cidade baianas" (p.138). Os hospitais e instituições de saúde construídos nesse período em Salvador concentraram-se em áreas já consolidadas da malha urbana, com exceção dos hospitais voltados para doenças infectocontagiosas, como a tuberculose, que foram implantados em setores periféricos.

Desse modo, o autor ressalta o papel das instituições de saúde na consolidação e na difusão da arquitetura moderna na Bahia, que ganha importância como modelo para outros programas, como por exemplo, escolas e residências. Como ele observa, "quase todos entre os principais protagonistas da arquitetura moderna na Bahia estiveram envolvidos em projetos de hospitais, como é o caso de Hélio Duarte, Diógenes Rebouças, José Bina Fonyat Filho e Flávio Régis do Nascimento, entre outros" (p.107). Ele destaca, principalmente, a atuação de Diógenes Rebouças, que se consolidou como o principal arquiteto local, mesmo sendo engenheiro-agrônomo de formação. Foi projetista atuante em Salvador desde a década de 1930 e desde 1943, como responsável pelo setor paisagístico e de planejamento físico do Escritório do Plano de Urbanismo da Cidade de Salvador, possibilitou que a arquitetura moderna baiana ganhasse fôlego (p.103).

Costa (2011) observa que os estudos sobre a relação entre história da assistência em saúde e arquitetura formam um campo novo de debate. A construção de equipamentos de saúde, além de se articular com as ciências e as tecnologias biomédicas, também é fruto do diálogo com as teorias arquitetônicas dominantes de suas épocas. Tanto a cidade como o hospital passam a ser lócus de procedimentos disciplinares com o objetivo de curar patologias sanitárias, sociais e espaciais, como já demonstrado. Costa (2011, p.55) observa:

No Brasil, o hospital moderno nasceu na passagem do modelo religioso para o modelo pavilhonar, em meados do século XIX, e procurava acompanhar a trajetória dessas construções na Europa, regidas primeiramente sob o princípio da construção em claustro, mas que sofreram profundas transformações depois do higienismo e ainda mais com os trabalhos de Louis Pasteur e a bacteriologia. Durante as primeiras décadas do século 
$\mathrm{XX}$, os projetos hospitalares estiveram sob a influência dessas ciências, porém atentos ao modelo que se consolidava nos EUA - a construção em bloco único, que é a tônica do modelo hospitalar até hoje.

Nesse capítulo, Andrade Jr. traz para o debate a arquitetura neocolonial dos postos de puericultura do interior do estado, as inovações em termos de programa, materiais e soluções construtivas trazidas da Escola de Puericultura Raimundo Pereira de Magalhães, inaugurada em 1937, ressaltando suas características modernas reforçadas, principalmente após a reforma, no final dos anos 1940, e a implantação do Hospital da Liga Bahiana contra a Mortalidade Infantil, construção em bloco único, inaugurada em 1965.

Além dos equipamentos relacionados à assistência em saúde infantil, trata daqueles construídos para assistência em saúde e pesquisa relativas à tuberculose, a saber, Instituto Brasileiro para a Investigação da Tuberculose, sanatório Santa Terezinha e as obras executadas pela Campanha Nacional contra a Tuberculose. O autor ressalta a principal edificação do ponto de vista arquitetônico e paisagístico para o combate à tuberculose: o Hospital Sanatório Santa Terezinha. Construído no subúrbio do Alto da Cruz do Cosme, periferia de Salvador, mais tarde, com a criação da Campanha Nacional Contra a Tuberculose, passou a ter vários pavilhões (modelo pavilhonar), formando o Parque Sanatorial Santa Terezinha. Juntamente com o Hospital do Instituto de Aposentadorias e Pensões dos Empregados em Transportes e Cargas (Iapetc), teve importante papel na infraestruturação da periferia de Salvador e na consolidação da arquitetura moderna na Bahia, com a posterior implantação nessas áreas do primeiro conjunto habitacional da cidade e de um dos oito complexos educacionais de tempo integral idealizados por Anísio Teixeira (p.127).

A revolucionária estética arquitetônica do Hospital Sanatório Santa Terezinha, com sua volumetria aerodinâmica, suas formas simples e sem ornamentação, suas cores claras, seus longos balcões lineares e, principalmente, a abertura desses espaços voltados aos banhos de sol dos pacientes para um entorno rural, permitindo a integração entre interior e exterior e a maximização do aproveitamento da luz natural, são características comuns a diversos hospitais e, mais especificamente, sanatórios para tuberculosos em todo o mundo (p.121).

Por último, são analisados outros exemplares da arquitetura modernista em Salvador, como o Hospital das Clínicas de Salvador, construído entre 1938 e 1943, exemplo do modelo do bloco único vertical, embrião do campus universitário de Canela (bairro para onde migraram as famílias abastadas da cidade de Salvador na virada do século XIX para o XX), além de outras instituições de saúde da região (p.128-132); os hospitais Santa Izabel, Naval e Santa Luzia construídos no bairro de Nazaré, que historicamente se constituiu em importante polo regional de instituições de saúde, e o Hospital Aristidez Maltez, em Brotas, bairro mais distante do centro tradicional (p.132-135).

Em relação ao órgão federal de preservação do patrimônio nacional (Instituto do Patrimônio Histórico e Artístico Nacional, Iphan), a valorização do patrimônio moderno e da arquitetura produzidos nas primeiras décadas do século XX é bastante recente. Ocorreram algumas exceções, como, por exemplo, o tombamento da igreja da Pampulha em Belo Horizonte, projetada por Oscar Niemeyer em 1942, e o do prédio do Ministério da Educação e Saúde, 
no Rio de Janeiro, que havia sido inaugurado apenas dois anos antes de seu tombamento. Como vários autores demonstram, a produção da arquitetura moderna e a preservação da arquitetura colonial foram importantes na construção da identidade nacional (Fonseca, 1997; Gonçalves, 1996; Leite, 2004), entretanto, a preservação do patrimônio moderno nacional pelo Iphan teve caráter de excepcionalidade. Contemporaneamente, Andrade Jr. afirma que o conflito dos usos e necessidades atuais desses equipamentos de saúde e a demanda por preservação de exemplares do patrimônio arquitetônico moderno brasileiro é o grande desafio a ser enfrentado.

É importante destacar na obra, a articulação entre pensamento médico-científico e arquitetura, que considera o patrimônio histórico e arquitetônico testemunho das "marcas ideológicas, jurídicas, culturais, políticas, profissionais, religiosas e científicas" (p.XVII) de uma sociedade. Sua análise permite dissecar concepções condensadas historicamente nesses documentos e edificações. O patrimônio arquitetônico e documental é a parte visível da rede de relações entre Igreja, Estado e ciência, e das disputas entre poder central e poderes locais na organização da assistência em saúde na Bahia durante o século XIX e primeira metade do XX.

Desse modo, é possível compreender, nas análises realizadas, a diversidade e a sobreposição de períodos e formas históricas nas concepções de saúde/doença e seus vínculos na apropriação dos espaços no tecido urbano, permitindo acessar, nos casos aqui tratados, os vários significados atribuídos, os vários usos, as funções sociais e a construção social de diferentes interesses e forças em disputa nos processos de modernização e urbanização levados a cabo no Brasil no período e contextos considerados.

\section{NOTA}

${ }^{1}$ Segundo Chalhoub (1996, p.35), a ideologia do higienismo é "um conjunto de princípios que estando destinados a conduzir o país ao 'verdadeiro', à 'civilização', implicam a despolitização da realidade histórica, a legitimação apriorística das decisões quanto às políticas públicas a serem aplicadas no meio urbano".

\section{REFERÊNCIAS}

CHALHOUB, Sidney.

Cidade febril: cortiços e epidemias na corte imperial. São Paulo: Companhia das Letras. 1996.

COSTA, Renato Gama-Rosa.

Apontamentos para a arquitetura hospitalar no Brasil: entre o tradicional e o moderno. História, Ciências, Saúde - Manguinhos, Rio de Janeiro, v.18, supl.1, p.53-66. 2011.

FONSECA, Maria Cecília Londres.

O patrimônio em processo: trajetória da política federal de preservação no Brasil. Rio de Janeiro: Editora da UFRJ; Iphan. 1997.

GONÇALVES, José Reginaldo.

A retórica da perda: os discursos do patrimônio cultural no Brasil. Rio de Janeiro: Editora da UFRJ; Iphan. 1996.
LEITE, Rogério Proença.

Contra-usos da cidade: lugares e espaço público na experiência urbana contemporânea. Campinas: Editora da Unicamp; Aracaju: Editora da UFS. 2004.

MARINS, Paulo César Garcez.

Habitação e vizinhança: limites da privacidade no surgimento das metrópoles brasileiras. In: Sevcenko, Nicolau (Org.). História da vida privada no Brasil: da Belle Époque à era do rádio, v.3. São Paulo: Companhia das Letras. p.131-214. 1998.

SEVCENKO, Nicolau. Introdução: o prelúdio republicano, astúcias da ordem e ilusões do progresso. In: Sevcenko, Nicolau (Org.). História da vida privada no Brasil: da Belle Époque à era do rádio, v.3. São Paulo: Companhia das Letras. p.7-48. 1998. 